IZABELA $€ U C$

https://orcid.org/0000-0002-0899-5802

izabela.luc@op.pl

Uniwersytet Śląski

Katowice, Polska
DOI: http://dx.doi.org/10.17651/ONOMAST.64.12

Onomastica LXIV, 2020

PL ISSN 0078-4648

\title{
NAZWY GÓRNOŚLĄSKICH KAWIARNI W ORBICIE KULTURY KONSUMPCYJNEJ
}

Słow a tematyczne: chrematonimia, nazwy kawiarni, kultura konsumpcyjna, Górny Śląsk

Słowa i znaki są jednym z najbardziej rozpoznawalnych przedmiotów konsumpcji (Ożóg, 2010, s. 126). Owa marketingowa tendencja wyraziście eksponuje się w strategiach operowania jednostkami językowymi — ich znaczeniem i doborem, zwłaszcza zaś w komunikatach, w których formalno-treściowe komponenty uwikłane są w rozmaite formy komercyjnych zależności. W ramach przyjętej przez nadawców strategii intencjonalnie spreparowane kolokacje słów, znaków diakrytycznych i interpunkcyjnych ulegają (kon)tekstowym aktualizacjom, zmierzając do przewartościowań desygnatów i waloryzacji przekazu, a jednostki leksykalne wpisane w model konsumpcji służą pomnażaniu charakterystycznych dla polszczyzny konsumpcyjnej ${ }^{1}$ (Ożóg, 2001, s. 243-248) operatorów perswazyjnych.

Na przykładzie swoistych dla kultury ponowoczesnej znaków językowych — współczesnych chrematonimów marketingowych ${ }^{2}$ można mówić o złożonym procesie manewrowania tworzywem z różnych odmian językowych uznanym przez nadawców za atrakcyjne dla kultury konsumpcyjnej ${ }^{3}$ nośniki znaczeń.

${ }^{1}$ Termin polszczyzna konsumpcyjna został po raz pierwszy użyty przez Kazimierza Ożoga w pierwszym wydaniu monografii „Polszczyzna przełomu XX i XXI wieku. Wybrane zagadnienia” (Ożóg, 2001). Znamienne dla polszczyzny konsumpcyjnej cechy, konstytuujące i umacniające jej odrębność, sprawiają, że konsoliduje ona swoiste znaczenia oraz paradygmaty myślenia.

${ }^{2}$ Artur Gałkowski, opierając się na szerokiej definicji chrematonimu, zaproponował określenie chrematonimia użytkowa; w jej obrębie wyróżniał trzy wewnętrznie podzielone podkategorie nazewnicze: chrematonimię marketingowa $(\mathrm{ChM})$, chrematonimię spolecznościowa $(\mathrm{ChS})$ i chrematonimię ideacyjna (ChI) (Gałkowski, 2011a, s. 51-53; Gałkowski, 2011b, s. 191-192).

${ }_{3}^{3}$ Pojęcie kultura konsumpcji interpretuję jako kulturę codzienności, wywyższającej wartości materialne i hedonistyczne, której cechą jest „,konsumowanie znaków, a nie samych towarów” (por. Dziura, 2009-2010: 276), dążenie konsumentów do nowoczesnego, bardziej atrakcyjnego stylu życia, tworzenie hiperrzeczywistości i rzeczywistości wirtualnej oraz nowej tożsamości człowieka, czerpanie z dorobku różnych kultur (por. Mazurek-Łopacińska, 2011, s. 47). 
Chrematonimy są interpretowane przez badaczy jako swoisty fenomen współczesności (Biolik i Duma, 2011), jako najliczniejsza i najbardziej produktywna, niejednolita, urozmaicona i prężna w systemie onimicznym oraz kulturze kategoria nazewnicza (Gałkowski, 2012, s. 187-188; Gałkowski, 2017, s. 54-71), jawi się obszerny i interesujący dla badacza materiał. Małgorzata Rutkiewicz-Hanczewska wykazuje, że ,[...] nazwy marketingowe reprezentują typ tekstów onimicznych o funkcji perswazyjnej, wpisując się w gatunek tzw. tekstów eferentnych, a zatem tworzonych z myślą o odpowiednim wykreowaniu za pomocą nazwy odpowiadającego mu denotatu" (Rutkiewicz-Hanczewska, 2014, s. 132).

Obserwacja górnośląskiej rzeczywistości komunikacyjnojęzykowej, oparta na analizie sposobów nominacji nazw użytkowych oraz ich roli w kształtowaniu językowego profilu kultury konsumpcyjnej, stała się źródłem inspiracji do opisu jednej z klas chrematonimów marketingowych — nazw kawiarni ${ }^{4}$, współtworzących miejski krajobraz nazewniczy regionu Śląska. Owemu oglądowi przypisano kilka celów: 1) ustalenie technik i typów nominacyjnych w zakresie wyboru tworzywa onimicznego; 2) opis modeli strukturalnych; 3) uchwycenie zmian znaczeniowych oraz (kon)tekstowej funkcjonalności wykładników językowych użytych do kreacji nazw omawianej kategorii. Wśród założonych celów mieszczą się również działania związane z próbą wykazania zakresu i częstotliwości stosowanych mechanizmów komponowania nazw handlowo-usługowych z uwzględnieniem strony formalnojęzykowej i określonych preferencji w wyborze powtarzalnych jednostek/schematów w akcie ich kreacji (por. Rutkiewicz, 2014, s. 136).

W artykule poddano analizie 203 nazwy kawiarni zgromadzonych w latach 2017-2019, które zanotowano w czasie bezpośredniej obserwacji górnośląskiej przestrzeni miejskiej Bytomia, Chorzowa, Jastrzębia-Zdroju, Łazisk Górnych, Mikołowa, Mysłowic, Katowic, Piekar Śląskich, Pszczyny, Rudy Śląskiej, Siemianowic Śląskich, Wodzisławia Śląskiego, Zabrza (i ich powiatów) oraz zaczerpnięto ze stron internetowych ${ }^{5}$. Reprezentatywny zasób nazewniczy opisano z perspektywy lingwistyki kulturowej ${ }^{6} \mathrm{i}$ pragmalingwistyki, uwzględniając właściwe dla skompilowanej metodologii rozwiązania badawcze oraz złożony polisystem regionalnych i komercyjnych uwarunkowań7.

${ }^{4} \mathrm{~W}$ artykule zastosowano synonimiczne określenia dla nazw kawiarni, por.: chrematonimy marketingowe, nazwy obiektu ustugowego, komercyjne nazwy, komercyjne twory onimiczne, nazwy handlowo-ustugowe, nazwy marketingowe.

${ }^{5} \mathrm{~W}$ tekście przywołano nazwy kawiarni w pisowni zgodnej z ich wersją zamieszczoną na stronach internetowych.

${ }^{6}$ Por. postulaty badawcze Roberta Mrózka związane z doborem metodologii (Mrózek, 2002, s. 23-35; Mrózek, 2004, s. 9-19).

${ }^{7}$ Zdaniem Aleksandry Cieślikowej ogląd materiału nazewniczego powinien przyjąć polimetodologiczny kierunek (Cieślikowa, 2011, s. 121). 
Zebrane przykłady nazw obiektów usługowych (por. Siwiec, 2012) można uznać za zróżnicowany formalnie i funkcjonalnie zbiór onimów ${ }^{8}$. W obrębie opisywanej klasy chrematonimów marketingowych zarejestrowano nazwy jedno-, dwu- i wieloczłonowe, powstałe w wyniku proprializacjii transonimizacji (głównie wtórnego wykorzystania antroponimów, geonimów i etnonimów) bez dodatkowych wykładników morfologicznych, oraz twory będące efektem kreacji formalnojęzykowej, stworzone przy użyciu odpowiednich technik i metod. Jako tworzywo onimiczne tych nazw wyzyskano jednostki wywodzące się z języka rodzimego (i jego odmiany gwarowej), leksemy o obcej proweniencji oraz struktury mieszane (hybrydy komponowane z odmiennych genetycznie podstaw).

Ustalenia badawcze, mające wykazać, czy w aktach kreacji nazw górnośląskich kawiarni dominują struktury i typy nominacyjne zawierające zbliżone znaczeniowo lub identyczne tworzywo językowe, wykazały kilka tendencji potwierdzających seryjność kreowania modeli onimicznych na Górnym Śląsku. Na tej podstawie wydzielono: 1) nazwy jedno- i kilkuskładnikowe (te przeważają ilościowo), identyfikujące rodzaj prowadzonej w obiekcie działalności usługowej, zawierające komponent semantyczny 'miejsce' — kawiarnia/kawiarenka lub 'produkt' - cafe, caffe, coffe, coffee; kaffet, kafo, kawa, kava; 2) inne kreacje nazewnicze, w tym - twory metaforyczne (abstrakcyjne) i aluzyjne o niejasnej motywacji lub motywacji magicznej (por. Palinciuc, 2010, s. 313) oraz struktury powstałe w wyniku transonimizacji. W zakresie przyjętej klasyfikacji nazw dokonano dalszego (wewnętrznego) ich podziału, który uzasadniono w trakcie analiz.

Rozpoznane typy inklinacji umożliwiają określenie znaczenia omawianej klasy chrematonimów w systemie onimicznym oraz ustalenie ich roli w kulturze konsumpcyjnej, wyrażającej się w sposobach odtwarzania w nazwach wartości i właściwości kultury konsumpcyjnej ${ }^{9}$. Uwzględniając owe determinanty, założono, że wielopłaszczyznowy ogląd nazw kawiarni, podporządkowany sugestiom Aleksandry Cieślikowej, ułatwi (ponad)regionalne porównanie różnych struktur nazewniczych ${ }^{10}$ oraz umożliwi wykazanie cech wspólnych i różnicujących w obrębie klas wywodzących się z tej samej kategorii.

${ }^{8}$ Por. przykładowe, starsze i nowsze syntezy badań w zakresie chrematonimii użytkowej: Breza, 1988a, 1998b; Kosyl, 2003; Rzetelska-Feleszko, 2007, 2009, 2010; Afeltowicz, 2000; Biolik, 2011; Gajewska, 2010; Gałkowski, 2011a, 2011b, 2012, 2014, 2015, 2017; Łuc, 2019; Siwiec, 2012.

${ }_{9}$ Mówiąc o cechach kultury konsumpcyjnej wyrażających się w sferze języka, ma się tu na myśli: polisemiczność, akcentowanie gier językowych, dowartościowanie intertekstualności, waloryzację przekazu, modę onimiczną przekładającą się na szczególną popularność wyboru określonych komponentów, modę na potoczność, tendencję do kreowania seryjnych modeli form przekazu oraz do ich skrótu i ekonomiczności środków językowych, kompilację jednostek odmiennych genetycznie i wywodzących się z różnych odmian językowych, mieszanie stylów, przewagę interpretacji nad obiektywnością, emocjonalizm (por. Ożóg, 2001, s. 250-253).

${ }^{10}$ Por. „Podstawowe różnice we właściwościach językowych różnych grup onimów płyną ze zróżnicowania cech obiektów świata zewnętrznego, odbitych w nazwach mieszczących się w poszczególnych kategoriach. Cechy musiały zostać zauważone i wyeksponowane przez nadających nazwy" (Cieślikowa, 1996, s. 7). 
Odpowiednio pogrupowane nazwy kawiarni, niezależnie od ich statusu, ewokują określony typ odbiorczych skojarzeń, sprzyjając dekodowaniu właściwemu, zgodnemu z konsumpcyjnymi założeniami ich twórców. Te komercyjne twory realizują funkcje konsumpcyjne (perswazyjno-marketingowe i wartościujące), budują wizerunek lokali, promują oferowane w obiektach produkty, przekonują o jakości świadczonych usług, przykuwają uwagę grupy docelowej odbiorców oraz wzmacniają i uatrakcyjniają przekaz.

\section{LEKSEMY KAWIARNIA/KAWA ORAZ ICH POCHODNE I OBCOJĘZYCZNE ODPOWIEDNIKI JAKO SERYJNE WYKŁADNIKI NAZEWNICZE}

W grupie nazw komponowanych z członem utożsamiającym kawiarnia, kawa, wyróżniającej się pod względem liczebności ( $74 \%$ wszystkich zgromadzonych nazw górnośląskich kawiarni), wynotowano chrematonimy o różnej genezie językowej tworzących je elementów, ale o podobnych motywacjach znaczeniowych. Owa swoistość motywacyjna zawarta w sposobach konstruowania nazw o komponentach rodzimego pochodzenia (1a), jak również nazw odwołujących się do zasobów leksykalnych języków obcych (1b) oraz nazw łączących elementy rodzime i obce (2c), zadecydowała o zaklasyfikowaniu ich do jednej grupy.

1a) W grupie nazw jedno- (ta okazjonalnie reprezentowana przez chrematonim o podstawie gwarowej Kafej ${ }^{11}$ ), dwu- i trzyskładnikowych o rodzimym pochodzeniu występują połączenia wyrazowe, w których członem deskrypcyjnym jest rzeczownik kawiarnia/kawiarenka (zawierający w swej semantyce element 'miejsce') oraz właściwy firmonim (najczęściej o szyku postpozycyjnym). Owe onimy, reprezentowane przez 49 formacji ( $24 \%$ wszystkich zgromadzonych określeń kawiarni), są determinowane właściwościami komponentów językowych (członów wyodrębniających, właściwych), których użyto w akcie ich nominacji, oraz przypisanymi im funkcjami.

Część chrematonimów omawianej klasy wskazuje na odbiorcę, poprzez odwołania do jego zainteresowań, pasji, upodobań (por.: Kawiarnia Artystyczna, Kawiarnia Fotograficzna, Kawiarnia Literacka, Kawiarenka Radiolla ${ }^{12}$, Kocia Kawiarnia Mruczkowo ${ }^{13}$ ), pozostałe opisują rodzaj i swoistość składanej oferty (por.: Cappucino Kawiarnia, Kawiarnia Coffeina, Kawiarenka Muffin, Kawiarnia

${ }^{11} \mathrm{~W}$ dalszej części tekstu, przywołując definicje słownikowe, posługuję się skrótami ich źródeł, których rozwinięcia znajdują się na końcu artykułu. Por. kafej/kafyj 'kawiarnia' (SGŚ, s. 124).

${ }^{12}$ Por. radiola 'dawny aparat radiowy umieszczony w jednej obudowie z innym sprzętem elektroakustyczny'.

${ }^{13}$ Zarówno sposób nazwania lokalu, jak i koncepcja towarzysząca jego powstaniu pokazują, że kawiarnia to nie tylko 'lokal, w którym można wypić kawę/herbatę, zjeść ciastko, porozmawiać', ale miejsce skupiające miłośników kotów. Podobną funkcję przypisano nazwie kawiarni Koci Zaułek. 
Ptyś) bądź oceniają jakość świadczonych usług (por.: Kawiarnia Srebrna Lyżeczka i Orient Express Kawiarnia) ${ }^{14}$.

Określenia kawiarni, zawierające w swej semantyce element 'miejsce', odwołują się do wartości, tradycji, historii (por. Kawiarnia Zabytkowa) oraz charakteryzują obiekt (por. Kawiarnia Za $\boldsymbol{S} z \boldsymbol{y} \boldsymbol{b} \boldsymbol{q}$ ). Pozostałe chrematonimy marketingowe wskazują na położenie obiektu, por. Kawiarnia 13.

Większość struktur lokalizujących obiekt stworzono przy użyciu wyrażenia przyimkowego, por.: Kawiarnia Na Pięterku, Kawiarnia Pod Wieża, Kawiarnia Pod Gronem, Kawiarnia Pod Róża, Kawiarnia Pod Tężnią. Wśród chrematonimów lokalizujących obiekt w sposób szczególny wyróżnia się formacja Kawiarnia Artystyczna Pod-Nad zbudowana na zasadzie zestawienia przyimków przestrzennych o przeciwstawnym znaczeniu; tym samym ową abstrakcyjną nazwę można uznać za formę gry onimicznej z odbiorcą.

W funkcji właściwej firmonimu wykorzystano też choronimy, etnonimy i toponimy, por.: Kawiarnia Argentynka, Kawiarnia Europa, Kawiarnia Hawana, Kawiarnia Mexico, Kawiarnia Tivoli, Kawiarnia Wawelska, które można powiązać z podróżami, dostojeństwem, historią i kulturą. Najwięcej nazw z tej grupy zawiera w strukturze metaforyczne określenie wskazujące na właściwy firmonim, por.: Kawiarnia Frayda, Kawiarnia Kaprys, Kawiarnia Marzenie, Kawiarnia Pokusa, Kawiarnia Co Bąź, Kawiarnia Po prostu, oraz nazwę o szyku prepozycyjnym Projekt Kawiarnia. Każdy z komponentów przypisany tym nazwom, jako swoisty dla kultury konsumpcyjnej operator perswazyjny, przywołuje odpowiednie konotacje i opisuje jakość oferty wyróżniającej dany obiekt, por.: frajda $<$ pot. frajda 'niezwykła przyjemność; radość', kaprys 'wysublimowane oczekiwanie; chwilowa zachcianka', marzenie 'pozytywna wizualizacja realizacji osobistych pragnien', pokusa 'nieodparta chęć skorzystania z czegoś'. Określenia co bądź i po prostu, wywodzące się z odmiany potocznej języka oraz leksem projekt 'rodzaj przedsięwzięcia', służą jako gwarant jakości oferowanych usług.

Kawiarnia Kawka oraz Kawiarnia Pozytywna Kawka pełnią potrójną funkcję: wyróżniającą, perswazyjną i wartościującą. Zawarty w nazwach hipokorystyczny komponent kawka waloryzuje oferty, a określenie pozytywna sugestywnie odwołuje się do odbiorczej oceny.

Wśród nazw górnośląskich kawiarni wynotowano 11 struktur zawierających w podstawie leksem kawa. Dwie z nich o charakterze metaforycznym pełnią funkcję estetyczną (por.: Malowana Kawa), dwie informacyjno-charakteryzującą (por.

${ }^{14}$ Intencjonalnie użyta w akcie nominacji nazwa Orient Express, ulegając procesowi transonimizacji, posłużyła wydobyciu konsumpcyjnych wieloznaczności. Orient Express jako nazwa luksusowego pociągu powiązana jest z oceną wysokiej jakości świadczonych usług i serwowanych w lokalu specjałów, samo zaś apelatywne określenie express nawiązuje do typu oferty — kawy podawanej z ekspresu (por. konotacje 'szybka kawa' oraz 'kawa, która natychmiast stawia na nogi'). 
Kawa i Zabawa ${ }^{15}$, 3 Siostry Bajgiel i Kawa), podpowiadającą odbiorcy, jakie oferowane mu atrakcje i specjały wyróżniają obiekt. Piątą, złożoną strukturę Karmnik. Kawa i ziarno ${ }^{16}$, można zaliczyć do nazw kreatywnych (por. ewokowane konotacje — karmnik: 1.< karmić 'miejsce konsumpcji i spotkań przy posiłku'; 2. karmnik 'rzecz, do której wkłada się wszelką karmę' oraz < karma 'prawo przyczyny i skutku' i kawa $\rightarrow$ ziarna kawy $\rightarrow$ najwyższa jakość produktu oferowanego w lokalu). Kolejną z nazw marketingowych, której wykładnikiem jest wieloznaczny i modny wyraz fokus, por. Fokus kawowy, odbiorca może powiązać z motywacją 'punkt, w którym skupiają się smakosze kawy'. Jedna z nazw kawiarni o podstawie kawa powstała w wyniku połączenia dwóch różnych elementów językowych motywujących powstanie nazwy, por. Stodkawa $<$ słodka + kawa. Stworzona w ten sposób komercyjna nazwa przywołuje kilka znaczeń, przekładających się na ofertę punktu usługowego (por. słodka kawa 'przyjemna w smaku' $\rightarrow$ oferta: kawa + słodycze, które można degustować, delektując się jej smakiem oraz homonim słodkawa, 'czyli nie do końca słodka, z lekkim posmakiem słodkości'). Dwie nazwy o podstawie kawa/cafe utworzono przy pomocy określeń temporalno-aluzyjnych (por:: Szybka kawa, Pora na kawe), gdzie leksemy szybka 'działająca natychmiastowo; pobudzająca do życia'; również 'szybko podana, taka, na którą nie czeka się długo' i pora 'odpowiedni czas na coś' pełnią funkcję wartościującego operatora aktywizującego zachowania komunikacyjne odbiorów. Dwie kolejne nazwy promują serwowane w lokalu wypieki i śniadania. Pierwsza z nich, motywowana hydronimem (Rawa - nazwa katowickiej rzeki) to zestawienie w postaci rymowanki, por. Rawa Jedzenie i Kawa, druga struktura o charakterze metaforycznym, która przyjęła postać oksymoronu, por. Kawa Stodkie Stone, sugeruje odbiorcy zróżnicowaną smakowo gamę polecanych specjałów.

1b) Zgromadzony zasób nazw górnośląskich kawiarni pokazuje, że ich twórcy chętnie korzystają z zasobów leksykalnych wywodzących się różnych języków ${ }^{17}$, dowodem czego są licznie zebrane chrematonimy marketingowe o wykładnikach: cafe, caffe, cofee, coffee, cofeina, coffeina, kava, kavi, kaffet, kafo, reprezentowane przez 56 formacji. Owe composita nazewnicze pochodzą z języka włoskiego, por.: Baccara Cafe < baccarà 'kryształowy', Cafe Amor< amore 'miłość', Cafe Gusto $<$ gusto 'smak, gust, przyjemność', Cafe Piccolo < piccolo 'mały, młody', Dolce

\footnotetext{
15 Jedną z oferowanych w kawiarni atrakcji jest opieka i dobra zabawa, jaką gwarantują dzieciom animatorzy, podczas gdy ich rodzice delektują się kawą.

${ }^{16}$ Por. też inne marketingowe nazwy górnośląskie, zawierające jako wykładnik formalny komponent karmnik - Poradnia dietetyczna Karmnik Zdrowia (Tychy).

${ }^{17}$ Owe preferencje nominacyjne we współczesnym nazewnictwie marketingowym opisywał Adam Siwiec (Siwiec, 2003, s. 549).
} 
Cafe < dolce 'słodkie', hiszpańskiego, por.: Cafe Animo < ánimo 'moc, odwaga', Cafe Coco < coco 'kokos', Cafe La Isla del Chocolate < la isla 'wyspa'. Zawarte w nich komponenty leksykalne odnoszą się wprost lub pośrednio do różnych wartości (por. miłość, życie; kryształ $\rightarrow$ bogactwo) lub doznań (por. moc i przyjemność), zwłaszcza smakowych (por. kokos i czekolada) — swoistych dla kultury konsumpcyjnej operatorów perswazyjnych, przykuwających uwagę odbiorców.

Najwięcej formacji obcych wywodzi się z języka angielskiego, por.: Coffe Feel, Coffe Heaven, Coffe Magic, Coffe Spots oraz Coffee Ways. Użyte do kreacji nazw określenia odwołują się do uczuć, wyjątkowych wrażeń, odpoczynku i okazji do spotkań. W nazwach Cofeina Corner $<$ ang. corner 'róg, zakątek, winkiel', 40th Street Cafe, Coffee City oraz Wall Street Cafe wyróżnia się deskrypcja lokalizacyjna, a w nazwie Industrial Cafe < industrial 'przemysłowa' posłużono się aluzją do cech górnośląskiego regionu. Skuteczność oddziaływania na odbiorców nazw o obcych podstawach, jak podkreśla Magdalena Graf, zależy od sposobu użycia i właściwości narzędzia językowego, przy pomocy którego przywołuje się określone obrazy, wyzyskuje się ich metaforyczność oraz emocjonalnie angażuje się odbiorcę w proces dekodowania zapisanych $\mathrm{w}$ onimach kulturowych znaczeń (Graf, 2015, s. 51-54).

Warte uwagi są również kreacje nazewnicze promujące alternatywne sposoby parzenia kawy, serwowane tam specjały, wyróżniające daną kawiarnię wśród innych, por.: Cofeina Bistro, Coffeina Cafe, Kofeina Mini oraz Cinnamon Cafe, Chococoffe, Karmello Cafe, Tost Cafe, Malekuta Cafe.

Nazwy typu Aromat Cafe, Caffe Moya, Elektric Cafe, STOP Cafe (zawierające w strukturze obce komponenty przyswojone do polszczyzny) oraz SO!Coffee ${ }^{18}$ (będącej połączeniem różnych elementów językowych i graficznych), sugestywnie zachęcają odbiorców do odwiedzenia tych miejsc.

Kilka formacji nazewniczych zawiera przekształcenia komponentu nazewniczego kawa, por. Kavi, Kafo (kavi< język esperanto 'ziarno kawy'), Kaffet ( $<$ język szwedzki 'kawa') oraz Local Kava, charakteryzując promowane przy ich pomocy obiekty. Trzy włoskie nazwy zawierają w podstawie leksemy wartościujące, które informują o panującym tam nastroju i klimacie oraz stylizacji obiektów, por.: Coccole di Caffe < coccole 'przytulna, miły nastrój', Cafe Sephia, CafeSorisso < sorisso 'uśmiech, radość, szczęście'.

Nazwy o obcej proweniencji, zawierające toponimiczne i topograficzne określenia, por.: Cafe Arosa, Cafe Cortina, Cafe Roma, Cafe Wenecja, Colorado Cafe,

18 Por. „SO!COFFEE to miejsce wytchnienia i relaksu - z miłą atmosferą, oryginalnym wystrojem i bogatą ofertą, w której każdy znajdzie coś dla siebie" (z opisu na stronie https://www. socoffee.pl [dostęp: 25.05.2019]). 
Colonia Cafe, Columbus Caffee, Laguna Cafe, przenoszą odbiorców w różne części świata i/lub krainy geograficzne.

W pięciu chrematonimach marketingowych omawianej kategorii człon cafe powiązano relacjami składniowymi z antroponimami, por:: Ann-Cafe, Cafe Horst, Cafe Paterman, Cafe Rene, Marco Cafe.

Pozostałe określenia kawiarni komponowane dwuskładnikowo z członem utożsamiającym cafe, powstały przy współudziale transonimizacji i posiadają muzyczne motywacje i konotacje, por.: Cafe Chopin, Cafe D-Moll (mollowa gama muzyczna ${ }^{19}$ ), Cafe Verdi; w jedną z nazw wpisano nazwisko hiszpańskiego architekta, por. Gaudi Cafe. Te cztery nazwy odwołują się do wartości estetycznych.

1c) Wśród wynotowanych określeń kawiarni, zawierających w swej strukturze powtarzalny człon utożsamiający cafe (i jego obcojęzyczne odpowiedniki) za interesującą można uznać grupę hybryd nazewniczych, reprezentowaną przez 36 struktur (to jest 18\% całości wyekscerpowanego materiału onimicznego), waloryzujących obiekty (por.: Ale Ciacho Cafe, Cafe Bosko, Secesja Cafe, Coffee Synergia Dobre Miejsce), wskazujących na typ odbiorcy (por.: Art Cafe Mak, Migawka Cafe ${ }^{20}$, Kawosz Cafe, Sport Cafe), opisujących charakter i zakres świadczonych usług (por.: Cafe Filiżanka, Czekoladka Cafe, Pianka Cafe). W obrębie chrematonimów zaklasyfikowanych do tej grupy wyróżniają się formacje motywowane literaturą (Cafeteria Maby Książę) i filmem (por. Rodzinka Cafe < nazwa serialu Rodzinka.pl). Pięć nazw utworzonych przy pomocy transonimizacji, por.: Pan Wiking Cafe, Krystyna Wraca z Wiednia Cafe, Cafe Piętka, Cafe Dan < Daniel, Danuta, Cafe Emi < Emilia, Emil, obrazuje kolejne techniki nominacji. Pierwsza konotuje skojarzenia związane z podróżami, egzotyką, odkrywaniem nowych lądów ( $\rightarrow$ smaków kawy), druga, nominowana okolicznościowo (sytuacyjnie), kompilując komponent antroponimiczny (imienniczy) z geonimem, reklamuje wiedeńskie sposoby parzenia i podawania kawy, trzecia i czwarta motywowane są antroponimicznie, piąta zaś akcentuje tradycje rodzinne.

Interesującą grupę reprezentują też chrematonimy marketingowe o śląskich podstawach, w których użyto jednostki leksykalnej cafe/kawa (por. CafeByfyj ${ }^{21}$,

19 Właścicielem jest Damian Moll.

${ }^{20}$ Por. migawka 'część aparatu fotograficznego'. Por. „Trudno nam odpowiedzieć, czym tak dokładnie jesteśmy. Na pewno Kawiarnią Speciallity [...]. W dodatku, zakładem fotograficznym oferującym zdjęcia do dokumentów, wywoływanie zdjęć i filmów [...]" (z opisu na stronie https:// migawkacafe.pl [dostęp: 25.05.2019]).

${ }^{21}$ Por. bifej/byfyj < niem. Büffet> 'kredens kuchenny' (SGŚ, s. 37); por. też ' [...] nieodłączny element prawdziwej śląskiej kuchni [...] Tworzy rodzinny, swojski klimat. Do dziś życie codzienne wielu śląskich rodzin koncentruje się w kuchni. Bifej jest trwałym elementem śląskiej tożsamości'(NŚS, s. 19). 
Gryfno $^{22}$ Cafe, Ino ${ }^{23}$ Cafe, Kawa i Maszkety ${ }^{24}$, Zicherka ${ }^{25}$ Cafe $^{26}$. Nazwy te przyjmują rozmaite konstrukcje, w których użyte operatory wartościujące typu ino < ‘tylko' w znaczeniu oceniającym < 'aż' i maszkety 'coś słodkiego, wybornego' oraz perswazyjne określenie same < 'wyłącznie', wzmacniają opis jakości usług świadczonych przez górnośląskie obiekty.

W strukturę jednego z komercyjnych określeń kawiarni, przyporządkowanego do tej grupy, wpisano niemiecki wariant nazwy miasta, w drugiej zaś nazwę regionu - Śląsk. Chrematonim marketingowy Cafe Kattowitz nawiązuje do historii i tradycji górnośląskiej metropolii; ów toponimiczny wykładnik Kattowitz utrwala w nowo powstałej formacji onimicznej funkcję pamiątkową i kulturotwórczą ${ }^{27}$. W nazwie lokalu Cyrulik Śląski Café (,,kawiarnia nasycona śląską kulturą i historią" ${ }^{28}$ ) można doszukać się motywacji muzycznej (Cyrulik sewil$s k i<$ opera Gioacchino Rossiniego) oraz kulturowej (por. cyrulik i jego synonimy: chirurg, felczer, balwierz < niem. barbier 'fryzjer' ${ }^{29}$. Podwójna nominacja nazwy - regionem, jego historią i kulturą oraz motywacją muzyczną potęgują perswazyjny efekt waloryzacji identyfikującego obiekt określenia.

Nazywając kawiarnie przy użyciu komponentu cafe, wyzyskano również metaforyczne zestawienia typu Cafe Zodiak, Cafe Bordo, Daglezja Cafe, przywołujące ciąg skojarzeń odnoszonych do jakości ofert lokali oraz ich wystroju.

Jedna z nazw katowickich kawiarni Caffe Bar No57 lokalizuje obiekt, zaś funkcję lokalizacyjno-charakteryzującą przypisano formacjom Cafe Kamienica i Cafe Zaszyta.

Odmienne sposoby promowania obiektów reprezentują formacje, w których seryjnie użyty człon deskrypcyjny cafe, zestawiany z właściwym firmonimem,

${ }^{22}$ Por. gryfny <niem. griffig > = zgrabny — 'przystojny, urodziwy' (SGŚ, s. 104).

${ }^{23}$ Por. ino 'tylko' (SGŚ, s. 117) i nazwę rybnickiej restauracji-winiarni InoWino.

${ }^{24}$ Por. maszkecić, maszkiecić <niem. Naschkätzchen> = łakocie — 'łasuchować, objadać się słodyczami' (SGŚ, s. 171).

${ }_{25}$ Por. zicherka: '1. <niem. Sicherheitsnadel> — agrafka; 2. <niem. Sicherheitslampe > zicher lampa - lampa górnicza służąca do sygnalizowania obecności metanu'; 3. Sicherheit $=$ bezpieczeństwo [...]' (SGŚ, s. 335).

${ }^{26}$ W nazwach o gwarowej genezie wartościujący zdaje się być leksem gryfnie, używany na co dzień w komunikacji górnośląskiej mikrowspólnoty do określenia wyglądu lub sprawności w wykonywaniu jakiejś czynności (w owej kreacji następuje rozszerzenie znaczenia gwarowego określenia), zaś leksem maszkety wykazuje szczególną popularność onimiczną.

${ }^{27}$ Warto tu dodać, że owa tendencja odsłania się też w nazwach restauracji Ślonsko Gościna i Szwarny Ślask. Por. szwarny ‘ładny, przystojny, uroczy, gracki, chwacki’ (SGŚ, s. 285).

${ }^{28}$ Por. https://www.cyrulikslaski.com/ (dostęp: 25.05.2019).

${ }^{29}$ Por. Też nazwę Cyrulik Śląski - Barber Shop \& Salon Piękności i wypowiedź właścicieli katowickiego lokalu usługowego ,[...] zamysłem Cyrulika Śląskiego było stworzenie miejsca na mapie regionu, w którym rządzą wartości kultury śląskiej: fach, solidność i gościnność” (z opisu na Portalu Miasta Katowice, http://www.portal.katowice.pl/promocja_cyrulikslaski.php). 
realizuje proces prowadzenia gier formą leksykalną i graficzną z odbiorcą. Wśród nazw kawiarni zaklasyfikowanych do tej grupy wynotowano bowiem struktury, w których operatorem synkretycznym są znaki \& oraz @ połączone z rozmaitymi określeniami, por.: Kaprys Food \& Cafe; Na Wspólnej coffe \& bistro; Café (a) Galery O’joj. Owe komercyjne hybrydy nazewnicze posiadają różne nominacje i przypisane im funkcje tekstowe — od abstrakcyjnej (estetycznej — por. Kaprys Food), charakteryzującej, aluzyjnej (Na Wspólnej to nazwa serialu obyczajowego) i fatyczną (por. użycie partykuły potocznej $O^{\prime} j o j$, imitującej zachwyt).

Za wyróżniający się sposób promowania obiektu można uznać określenie kawiarni Caffetedra. Jeśli założymy, że nazwa powstała od połączenia wyrazów caffe + katedra, wówczas przywołuje ona wartości duchowe i swoisty klimat panujący w lokalu; tym samym, jako oryginalna formacja zamyka klasyfikacyjny rejestr hybryd nazewniczych — komercyjnych nośników kultury konsumpcyjnej.

\section{INNE KREACJE NAZEWNICZE NA USŁUGACH KULTURY KONSUMPCYJNEJ}

Poza opisanymi sposobami kreowania nazw mieszczą się, zaklasyfikowane do odrębnej grupy, struktury onimiczne komponowane przy pomocy różnych strategii nominacyjnych i technik, pełniących w obrębie kultury konsumpcyjnej kolejne funkcje.

Przypisane do tej grupy twory metaforyczne (abstrakcyjne) i aluzyjne o niejasnej motywacji lub motywacji magicznej (2a) oraz struktury nazewnicze komponowane przy udziale określeń z innych kategorii onimicznych (2b) liczą zbiór 53 nazw (to jest 26\% spośród wszystkich zebranych górnośląskich nazw kawiarni). Większość z nich potwierdza odmienne od wcześniej opisywanych technik nominacyjnych, stosowanych w ich obrębie, oraz tendencje do ich cykliczności. W odróżnieniu jednak od opisywanej uprzednio grupy chrematonimów komponowanych przy pomocy wykładnika cafe, wśród nazw omawianej kategorii okazjonalnie (sześciokrotnie) pojawiły się nazwy odwołujące się do zasobów leksykalnych języków obcych.

2a) Za swoiste w tej grupie uznać można nazwy metaforyczne (reprezentowane przez 38 przykładów), służące reklamie i promocji wyróżnianych przy ich pomocy obiektów. Nazwy te motywowane nazwami mitologicznymi typu Ikar i Olimpia, pełnią funkcję intertekstualną i wartościującą, odwołując się do wiedzy odbiorców na temat antycznych symboli ( $\rightarrow$ Olimpia 'miejsce kultu Zeusa') i ponadczasowych wartości (Ikar $\rightarrow$ 'dążenie/ambicja do realizacji celów'). Pozostałe nazwy, jak: Bialy Labędź, Kolorowa, Poza Czasem i Sultan, przywołują skojarzenia baśniowe oraz oniryczno-retrospektywne; są semantycznie 
powiązane z dostojeństwem, estetyką, tradycją, egzotyką, podróżami i dobrobytem. Za wyróżniające się w tej grupie określenia kawiarni można uznać Żółty Młynek $^{30}$ oraz komercyjne nazwy o charakterze bajkowo-magicznym i mitologicznym, reprezentowane przez formacje $\boldsymbol{S z}$ uflandia (jako odwołanie do filmu Kingsajz, wyreżyserowanego przez Janusza Machulskiego, w którym część akcji toczy się w krainie zwanej Szuflandia) i Meteor (w kulturze rzymskiej meteor był zapowiedzią doniosłych wydarzeń).

Estetyczne funkcje przypisano nazwom motywowanym określeniami z pola znaczeniowego rośliny, por.: Agawa, Irys, Lawenda, Stokrotka. Jedna z nazw o obcej podstawie nominowana określeniem z pola znaczeniowego ptaki (por. Flamingoo) konotuje skojarzenia związane z egzotyką i podróżą. Pozostałe, licznie reprezentowane formacje, pełnią funkcje waloryzująco-charakteryzujące i lokatywne. Za wartościujące obiekt nazwy kawiarni uznać można chrematonimy użytkowe typu Gracja ( $\rightarrow$ 'urokliwa'), Krysztalowa ( $\rightarrow$ 'bogata, dostojna'), Retro ( $\rightarrow$ 'stylowa'), Stoneczna ( $\rightarrow$ 'jasna, optymistyczna') oraz Miła i Milusia $(\rightarrow$ 'pozytywna, przyjemna'). Inne zaś twory, jak: Biała Brama, Stara Drukarnia, Posesja, 13 Kawiarnia oraz Cichy Kacik, Zacisze, Zielony Zaułek, charakteryzują w sposób (bez)pośredni identyfikowane nimi obiekty — opisują elementy ich aranżacji i otoczenie, w pobliżu którego się znajdują.

Ogląd chrematonimów komponowanych tworzywem regionalnym potwierdza okazjonalną obecność nazw jednotematowych, bez kreacji formalnojęzykowej

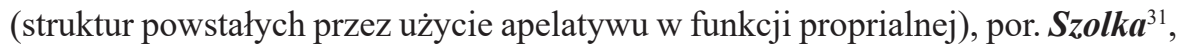
w której semantycznie przywołano leksem gwarowy powiązany z rodzajem oferowanych specjałów.

Kilka nazw kawiarni motywowanych jest leksemami i wyrażeniami kojarzącymi się muzycznie, np. Brunetki Blondynki (por. tytuł piosenki Jana Kiepury Brunetki, blondynki) oraz Bolero (utwór Maurice'a Ravela) i Carmen (opera Georges'a Bizeta).

Ciekawa jest etymologia nazwy gliwickiej kawiarni Lwowskie przyszepty (< przyszepty w gwarze lwowskiej oznaczają 'rozmowy lub kawiarniane ploteczki') o złożonej genezie ${ }^{32}$.

W aktach kreacji nazw cukierni-kawiarni Legalne Słodycze oraz Moja Bajka przywołano też inne metaforyczno-kulturowe skojarzenia, sugestywnie

\footnotetext{
${ }^{30}$ Rybnicka klubokawiarnia Żółty Młynek ,[...] to nie tylko gastronomia, ale również inicjatywy twórcze kształtujące atmosferę i łączące ludzi. To [...] nie tylko kawiarnia, ale i klub osób otwartych, myślących, którzy [...] patrzą na świat pozytywnie" (Furmanowicz, 2014).

${ }^{31}$ Por. szolka $<$ niem. Schale $=$ czarka, filiżanka $>$ - szklanka, filiżanka' (SGŚ, s. 276).

${ }^{32}$ Lwowskie przyszepty to tytuł wiersza autorstwa właścicielki kawiarni, lwowianki i poetki, której przodkowie osiedlili się w Gliwicach po II wojnie światowej (Kałębasiak, 2005).
} 
nakłaniające do skorzystania z oferty. W nazwie Legalne Słodycze, dzięki użyciu leksemu legalny, dokonuje się oceny produktu wartego degustacji, wytwarzanego wedle tradycyjnej receptury z najlepszych jakościowo składników, zaś nazewnicze określenie obiektu Moja Bajka, zawierające zaimek dzierżawczy mój oraz wartościujący komponent bajka 'coś wymarzonego, niepospolitego, wyjątkowego, magicznego', narzuca odbiorcy konsumpcyjny punkt widzenia ${ }^{33}$.

Do zaskakujących sposobów onimicznego wyróżniania kawiarni wydają się należeć określenia konotujące pejoratywne skojarzenia, por. nazwy: Bankrut (którą to nazwę można też uznać jako aluzję do filmu Igora Maslennikova), Belfegor (por. belfegor 'mitologiczny diabeł') i Pukawka (por. pukawka: 1. 'lekceważąco o broni palnej'; 2. 'zabawka dziecięca, wydająca odgłos podobny do wystrzału').

Wśród zebranych nazw górnośląskich kawiarni, których celem jest wyróżnianie, reklama i promocja, warte uwagi są też kompozycje w postaci zestawień. Zestawienie kliszowane reprezentuje kalka włoskiego określenia Stodkie Życie (por. dolce vita), a formację zawierającą znak diakrytyczny \#34 (będący wytworem kultury konsumpcyjnej) nazwa \#Bez cukru (por. też hasło reklamowe promujące lokal Lubię kawę, więc piję \#bez cukru). Dzięki onimicznemu zestawieniu Miss Cupcake < miss 'pani' + cupcake (termin amerykański; 'małe ciastko w papierowej foremce') oraz Dolce Vita < 'słodkie życie' promuje się swoistość oferty i wyróżnia obiekt.

Abstrakcyjne nazwy FiftyFifty < ang. fifty-fifty 'pół na pół; po połowie', LoLove (onimiczna gra z odbiorcą wyrażająca się w formie nietypowego połączenia leksemów: skrótu powitania hello 'witam' + love 'miłość') oraz $\boldsymbol{W}$ antryju $\boldsymbol{n a} \boldsymbol{b y f y j u} \boldsymbol{u}^{35}$ (część rymowanego powiedzenia, którego Ślązacy używają, akcentując swoistość swojej mowy) przykuwają uwagę odbiorców oryginalną strukturą i znaczeniem.

Swoista jest również formacja Ludiversum, kompilująca leksemy łacińskie ( $<$ charta ludi 'karta do gry' + uniwersum 'wszechświat' $\rightarrow$ 'świat gier, zabaw'), wskazująca na typ odbiorców — miłośników gier planszowych.

2b) Kilkanaście (14) chrematonimów omawianej klasy skomponowano przy współudziale określeń wywodzących się z innych kategorii nazewniczych. $\mathrm{W}$ tym też celu przywołano imiona oficjalne lub ich formy hipokorystyczne ${ }^{36}$

${ }^{33}$ Za równie sugestywne uznać też można nazwy kawiarni-lodziarni Lodowato, Lodomania i Smakomania Cafe oraz nazwę Kofeinka, derywowaną hipokorystycznie.

${ }^{34}$ \# (hashtag) to znak wykorzystywany w aktach przetwarzania informacji, głównie przez użytkowników w mediach społecznościowych. Znak ten pomaga wyróżniać istotne komunikaty, porządkować nadrzędne treści i zadania, ułatwiając ich dotarcie do odbiorców.

${ }^{35}$ Por. całość rymowanej wypowiedzi: $W$ antryju na byfyju stoi szolka tyju ' $\mathrm{w}$ przedpokoju na kredensie stoi szklanka herbaty' [I.Ł.].

${ }^{36}$ Kwestię derywatów uzualnych pochodzących od antroponimów opisała Rogowska-Cybulska (2018, s. 243-258). 
(por.: Amadeusz, Jacek, Roxana, Zbyszko; Piotruś, Walentynka ${ }^{37}$ ). W jednej z kompozycji aluzyjnie użyto imienia wpisanego w familijną zależność, por. Krystyna i Córki. W funkcji identyfikującej właścicieli, przy pomocy przyimka $u$, stworzono nazwy $\boldsymbol{U}$ Fiolków i $\boldsymbol{U}$ Kuśnierza; por. też nazwy kawiarni $\boldsymbol{U}$ Taty. Etnonim Eskimos posłużył twórcom do kreacji nazwy wyróżniającej obiekt i jego ofertę (lody cassate), zaś niepowtarzalną jakość świadczonych usług promuje nazwa Mount Blanc, motywowana oronimem (por. konotacja $\rightarrow$ najwyższy szczyt — 'najwyższa jakość').

Górnośląska nazwa kawiarni Barbórka (< św. Barbara — patronka górników) odwołuje się do nazwy tradycyjnego święta górniczego i pełni funkcję kulturotwórczo-tożsamościową. Nazwa ta zamyka klasyfikacyjny rejestr górnośląskich chrematonimów użytkowych, funkcjonujących w przestrzeni kultury konsumpcyjnej.

\section{ZAKOŃCZENIE}

Analiza nazw górnośląskich kawiarni obliguje do sformułowania kilku wniosków. Zaprezentowany materiał potwierdza, że chrematonimy marketingowe reprezentują niejednolitą semantycznie i strukturalnie kategorię nazewniczą. Użyte do ich kreacji komponenty (wywodzące się zarówno od apelatywów rodzimych, jak i o obcej proweniencji oraz od nazw z innych kategorii onimicznych), ulegając odpowiednim procesom, ułatwiają konstrukcję niejednorodnych nazw, podlegających konsumpcyjnym konceptom. Powstałe w ten sposób struktury dowodzą seryjności ich użyć (powtarzalności nominacyjnej), poświadczając jednocześnie kilka innych, charakterystycznych dla kultury ponowoczesnej tendencji, jak: skłonność do językowej internalizacji, do skrótu i ekonomiczności środków językowych, do kompilowania jednostek z różnych odmian językowych, do wieloznaczności, do operowania tworzywem gwarowym i prowadzenia gier językowych z odbiorcą oraz dowartościowanie intertekstualności i waloryzacja przekazu.

W marketingowym krajobrazie nazewniczym Górnego Śląska ujawniają się trzy tendencje językowe: rodzima, obca oraz mieszana, będąca efektem przenikania się dwóch pierwszych. O typie kreacji nazw rodzimych przesądzają nie tylko dwa leksemy (jako człony deskrypcyjne nazwy określające firmonim właściwy) kawiarnia i kawa (jako komponenty firmonimu właściwego), ale też określenia metaforyczne, aluzyjne, wartościujące, będące ich strukturalnymi wykładnikami, i nazwy stworzone przy pomocy innych kategorii onimicznych.

${ }^{37}$ Por. też walentynka 'krótki wiersz i laurka zawierające wyznanie miłosne lub komplement, którymi obdarowuje się wybrane osoby w dniu św. Walentego'. 
Nazwy komponowane przy użyciu zapożyczeń językowych oraz stworzone przy ich współudziale hybrydy nazewnicze (liczące łącznie 91 kompozycji; $45 \%$ całości zebranego materiału onimicznego) ewokują skojarzenia związane z egzotyką, podróżami, odkrywaniem tajemnic i smaków świata. Swym brzmieniem i konstrukcją zachęcają odbiorców do zakupu aromatycznych napojów parzonych klasycznymi i alternatywnymi metodami oraz degustacji słodyczy przyrządzanych wedle oryginalnych receptur.

Za interesujące w grupie nazw rodzimych uznać można dwanaście formacji, których wykładnikiem formalnym są leksemy o podłożu gwarowym. Wpisane w strukturę chrematonimów marketingowych gwaryzmy waloryzują omawianą klasę nazewnictwa, „strukturalizują” i wyróżniają przestrzeń onimiczną subregionu Śląska. Nazwy te, równolegle do funkcji identyfikacyjnej, wyróżniającej i reklamującej, pełnią funkcje perswazyjne, faktyczne, ekspresywne i emocjonalne.

W przestrzeni kreacyjnej każdej z wymienionych tendencji można mówić o tzw. cyklu produkcyjnym nazw (por. Graf, 2015, s. 51), powtarzalnych preferencjach w wyborze jednostek służących ich identyfikacji i promocji, poświadczających zjawisko efemerycznej mody onimicznej (por. Jaracz, 2002, s. 177-185) na określone leksemy (por. regionalne gryfny, maszkety), semantyczne kompozycje i struktury (zwłaszcza te z komponentem kawa/cafe), przejawiających cechy kultury konsumpcyjnej.

Zebrane przykłady nazw obrazują wielość mechanizmów, przy użyciu których powstały zróżnicowane formalnie twory przykuwające uwagę odbiorców (por.: \#Bezcukru; Café @ Galery O'joj, LoLove, SO!Coffe), dowodzące kreatywności ich twórców.

Większość nazw omawianej klasy zawiera w strukturze operatory wartościujące, swoiste dla polszczyzny konsumpcyjnej, por.: Eden, Gryfno Cafe, Kawiarnia Dobry Adres, Magic, Pro-Ice Kawiarnia-Cukiernia.

Spora grupa górnośląskich nazw motywowanych była określeniami związanymi z literaturą, filmem i muzyką (por.: Kafeteria Mały Ksiażę, Na Wspólnej coffe \& bistro, Cafe d-Moll, Helikon) oraz określeniami użytymi metaforycznie i aluzyjnie (por.: Cukiernia-Kawiarnia Legalne Stodycze, Industrial Cafe, Szuflandia).

Kilka nazw komponowano przy użyciu wartościującego komponentu leksykalnego słodki, wpisanego w człon właściwy firmonimu, por.: Kawa Stodkie Stone, Stodkawa, Stodkomania; por. też nazwy Dolce Cafe i Stodkie Życie.

Wśród nazw górnośląskich kawiarni wyróżniają się też formacje związane ze specjalnościami lokalu, por.: Miss Cupcake, Tost Cafe, 3 Siostry Bajgiel, reklamujących jego klimat i wizualizujących doznania smakowe (por.: Caffe Synergia Dobre Miejsce, Secesja Cafe, Stylowa), oraz nazwy wyróżniające odbiorców (por.: Kawosz Kafe, Kocia Kawiarnia Mruczkowo, Ludiversum).

Konkludując, analizowane onimy użytkowe utwierdzają w przekonaniu, że chrematonimia ,[...] to obecnie hiperkategoria nazewnicza, w której dokonują 
się procesy niespotykane pod względem ilościowym i jakościowym w innych grupach nazw własnych" (Rutkowski, 2016, s. 21). Górnośląskie nazwy kawiarni potwierdzają status i znaczenie chrematonimów marketingowych w dynamice onimicznej języka (por. Gałkowski, 2007, s. 495-508) oraz odsłaniają mechanizmy ich funkcjonowania w orbicie kultury konsumpcyjnej.

\section{LITERATURA}

Afeltowicz, B. (2000). Nazwy lokali gastronomicznych w Szczecinie [Names of gastronomic establishments in Szczecin]. W: M. Czachorowska, Ł.M. Szewczyk (red.), Onomastyka polska a nowe kierunki językoznawcze [Polish onomastics and new linguistic trends] (s. 195-209). Bydgoszcz: Wydawnictwo Uczelniane WSP w Bydgoszczy.

Biolik, M. (2011). Modele strukturalne nazw własnych przedsiębiorstw i lokali branży gastronomicznej w województwie warmińsko-mazurskim [Structural models of the names of gastronomic establishments in the Warmia-Mazury voivodeship]. W: M. Biolik, J. Duma (red.), Chrematonimia jako fenomen wspótczesności [Chrematonymy as a phenomenon of modern times] (s. 59-78). Olsztyn: Wydawnictwo Uniwersytetu Warmińsko-Mazurskiego.

Biolik, M. i Duma, J. (red.). (2011). Chrematonimia jako fenomen wspótczesności [Chrematonymy as a phenomenon of modern times]. Olsztyn: Wydawnictwo Uniwersytetu Warmińsko--Mazurskiego.

Breza, E. (1988a). Nazwy lokali gastronomicznych w obecnym województwie gdańskim [Names of gastronomic establishments in the Gdańsk province]. Zeszyty Naukowe Uniwersytetu Gdańskiego. Prace Językoznawcze, 14, 115-123.

Breza, E. (1988b). Nazwy obiektów i instytucji związanych z nowoczesną cywilizacją (chrematonimy) [Names of objects and institutions related to modern civilization (chrematonyms)]. W: E. Rzetelska-Feleszko (red.), Polskie nazwy własne. Encyklopedia [Polish proper names. Encyclopedia] (s. 334-361). Warszawa-Kraków: Towarzystwo Naukowe Warszawskie; Instytut Języka Polskiego PAN.

Cieślikowa, A. (2011). Jakie korzyści daje onomastyce chrematonimia? [What are the benefits of chrematonymy for onomastics?]. W: M. Biolik, J. Duma (red.), Chrematonimia jako fenomen wspótczesności [Chrematonymy as a phenomenon of modern times] (s. 113-123). Olsztyn: Wydawnictwo Uniwersytetu Warmińsko-Mazurskiego.

Dziura, M. (2009-2010). Kultura konsumpcji [Culture of consumption]. Roczniki Wydzialu Nauk Prawnych i Ekonomicznych KUL, 5-6(2), 271-286.

Furmanowicz, B. (2015, 13 kwietnia). Duszpasterstwo otworzyło klubokawiarnię. „Żółty Młynek” zobaczył nawet abp Skworc! Rybnik - Portal informacyjny miasta Rybnik. https://www.rybnik.com.pl/wiadomosci,duszpasterstwo-otworzylo-klubokawiarnie-8222-zolty-mlynek-8221-zobaczyl-nawet-abp-skworc,wia5-3273-26899.html

Gajewska, U. (2010). Nazwy lokali gastronomicznych w Rzeszowie [Names of gastronomic establishments in Rzeszów]. W: J. Lizak, E. Błachowicz (red.), Rzeszów i okolice: język - historia - kultura [Rzeszów and surroundings: language — history — culture] (s. 87-96). Rzeszów: Wydawnictwo Uniwersytetu Rzeszowskiego.

Gałkowski, A. (2007). Socjoideonimy a chrematonimy — miejsce nazw organizacji i inicjatyw społecznych w dynamice onimicznej języka [Socioideonyms and chrematonyms - the place of the names of organizations and social initiatives in the onymic dynamics of language]. W: A. Cieślikowa, B. Czopek-Kopciuch, K. Skowronek (red.), Nowe nazwy własne - nowe tendencje badawcze [New proper names — new research trends] (s. 495-508). Kraków: Wydawnictwo Pandit. 
Gałkowski, A. (2011a). Chrematonimy w funkcji kulturowo-użytkowej. Onomastyczne studium porównawcze na materiale polskim, włoskim, francuskim [Chrematonyms in the cultural-functional context. An onomastic comparative study based on Polish, Italian and French resources] (wyd. 2). Łódź: Wydawnictwo Uniwersytetu Łódzkiego.

Gałkowski, A. (2011b). Chrematoonomastyka jako autonomizująca się subdyscyplina nauk onomastycznych [Chrematoonomastics as an autonomous subdiscipline of onomastic sciences]. W: M. Biolik, J. Duma (red.), Chrematonimia jako fenomen współczesności [Chrematonymy as a phenomenon of modern times] (s. 181-193). Olsztyn: Wydawnictwo Uniwersytetu Warmińsko-Mazurskiego.

Gałkowski, A. (2012). Propozycje a rozstrzygnięcia terminologiczno-pojęciowe dotyczące chrematonimii [Proposals and terminological and conceptual decisions regarding chrematonymy]. W: I. Łuc, M. Pogłódek (red.), W komunikacyjnej przestrzeni nazw własnych i pospolitych. Księga jubileuszowa dedykowana Profesorowi Robertowi Mrózkowi [In the communicative space of proper and common names. Jubilee book dedicated to Professor Robert Mrózek] (s. 189-200). Katowice: Wydawnictwo Uniwersytetu Śląskiego.

Gałkowski, A. (2014). Motywacja w procesach chrematonimii marketingowej [Motivation in the processes of marketing chrematonymy]. Poznańskie Spotkania Językoznawcze, 27, 63-72.

Gałkowski, A. (2015). Funkcja marketingowa chrematonimów w przestrzeni gospodarczej [The marketing function of chrematonyms in the economic sphere]. W: I. Sarnowska-Giefing, M. Balowski, M. Graf (red.), Funkcje nazw wlasnych w kulturze i komunikacji [Functions of proper names in culture and communication] (s. 171-180). Poznań: Wydawnictwo Uniwersytetu Adama Mickiewicza w Poznaniu.

Gałkowski, A. (2017). Chrematonimia w kulturze współczesnej [Chrematonymy in contemporary culture]. Onomastica, 61(1), 54-71.

Graf, M. (2010). Onimiczna waloryzacja przestrzeni miejskiej [Onymic valorization of urban space]. W: E. Umińska-Tytoń (red.), Ilość — wielkość — wartość (s. 79-92). Łódź: Archidiecezjalne Wydawnictwo Łódzkie.

Graf, M. (2015). Onimy marketingowe - między informacją a perswazją [Marketing names between information and persuasion]. LingVaria, 1(19), 49-59.

Jaracz, M. (2002). Uwagi na temat mody językowej w wybranych systemach nazw własnych [Comments on language fashion in selected proper names systems.]. W: K. Wojtczuk (red.), Moda jako problem lingwistyczny [Fashion as a linguistic problem] (s. 177-185). Siedlce: Wydawnictwo Akademii Podlaskiej.

Kałębasiak, Ł. (2005, 16 listopada). Lwowskie Przyszepty w Gliwicach. Wyborcza.pl. http://katowice.wyborcza.pl/katowice/1,35063,3017459.html

Kortko, D. i Jodliński, L. (red.). (2010), Antologia. Najpiękniejsze śląskie słowa [Anthology. The most beautiful Silesian words]. Katowice: Muzeum Śląskie.

Kosyl, C. (2003). Chrematonimia [Chrematonymy]. W: E. Rzetelska-Feleszko, A. Cieślikowa, J. Duma (red.), Stowiańska onomastyka. Encyklopedia [Slavonic onomastics. Encyclopedia] (t. 2, s. 370-375), Warszawa-Kraków: Towarzystwo Naukowe Warszawskie; Instytut Języka Polskiego PAN.

Łuc, I. (2019). Chrematonimy marketingowe o podstawie gwarowej jako nośnik wartościowania przestrzeni Górnego Śląska [Marketing chrematonyms with a dialectal base as a carrier for valuing the space of Upper Silesia]. W: A. Rygorowicz-Kuźma, K. Rutkowski (red.), Nazwy własne w języku, literaturze i kulturze. Księga jubileuszowa dedykowana Profesor Zofii Abramowicz [Proper names in language, literature and culture. Jubilee book dedicated to Professor Zofia Abramowicz] (s. 384-418). Białystok: Wydawnictwo Uniwersytetu w Białymstoku.

Mazurek-Łopacińska, K. (2011). Postmodernistyczna kultura konsumpcyjna w kształtowaniu popytu i stylów życia współczesnego konsumenta [Postmodern consumption culture in shaping the demand and lifestyles of the modern consumer]. Konsumpcja i Rozwój, 1, 47-57. 
Mrózek, R. (2002). Dorobek i perspektywy onomastyki polskiej [Achievements and perspectives of Polish onomastics]. Onomastica, 47, 23-35.

Mrózek, R. (2004). Nazwy własne jako przedmiot badawczy onomastyki [Proper names as a research subject of onomastics]. W: R. Mrózek (red.), Nazwy własne w języku, kulturze $i$ komunikacji społecznej [Proper names in language, culture and social communication] (s. 9-19). Katowice: Wydawnictwo Uniwersytetu Śląskiego.

Ożóg, K. (2001). Polszczyzna przełomu XX i XXI wieku. Wybrane zagadnienia [Polish language at the turn of the 20th and 21st centuries. Selected issues]. Rzeszów: Otwarty Rozdział.

Ożóg, K. (2010). Współczesne relacje między językiem polskim a kulturą [Contemporary relations between Polish language and culture]. W: M. Karwatowska, A. Siwiec (red.), Przeobrażenia w języku i komunikacji medialnej na przełomie XX $i$ XXI wieku [Transformations in language and media communication at the turn of the 20th and 21st centuries] (s. 121-131). Lublin: BEST PRINT.

Palinciuc, E. (2010). W nazewniczym tyglu krakowskich restauracji, kawiarni, klubów [In the naming melting pot of Krakow restaurants, cafes and clubs]. W: I. Sarnowska-Giefing, M. Graf (red.), Miasto w perspektywie onomastyki i historii [City in the perspective of onomastics and history] (s. 391-401). Poznań: Wydawnictwo Poznańskiego Towarzystwa Przyjaciół Nauk.

Podgórscy, B. i A. (2008). Słownik gwar śląskich. Godómy po naszymu, czyli po śląsku [Dictionary of Silesian dialects. We speak our language, that is, Silesian]. Katowice: KOS.

Rogowska-Cybulska, E. (2018). Goździkowa przypomina... O derywatach słowotwórczych będących nazwami własnymi w tekstach reklam [Goździkowa przypomina... Concerning the word formation of proper names in the texts of advertisements]. Onomastica, 62, 243-258.

Rutkiewicz-Hanczewska, M. (2014). Moda w zakresie morfologii współczesnych emporionimów [Fashion in morphology of contemporary emporionyms]. Poznańskie Spotkania Językoznawcze, 27, 135-144.

Rutkowski, M. (2016). Status obiektów i zasięg funkcjonowania nazw a ogólne tendencje nazwotwórcze [The status of name-objects, the social range of names and general naming tendencies]. Onomastica, 60,13-26.

Rzetelska-Feleszko, E. (2003). Nazwy dzisiejszych sklepów i firm w aspekcie kulturowym [Names of modern stores and companies in the cultural aspect]. W: Z. Kaleta (red.), Nazwy własne a kultura. Polska i inne kraje stowiańskie (s. 183-195). Warszawa: Slawistyczny Ośrodek Wydawniczy.

Rzetelska-Feleszko, E. (2007). Onomastyka kulturowa [Cultural onomastics]. W: A. Cieślikowa, B. Czopek-Kopciuch, K. Skowronek (red.), Nowe nazwy wtasne - nowe tendencje badawcze [New proper names - new research trends] (s. 57-62). Kraków: Wydawnictwo Pandit.

Rzetelska-Feleszko, E. (2009). Obecne nazwy firmowe w Polsce i Europie [Current company names in Poland and Europe]. Onomastica, 43, 267-268.

Rzetelska-Feleszko, E. (2010). Podstawy leksykalne obecnych nazw sklepów i firm [Lexical foundations of modern store and company names]. W: J. Mazur (red.), Stownictwo wspótczesnej polszczyzny w okresie przemian [Vocabulary of modern Polish in a time of change] (s. 141-148). Lublin: UMCS.

Siwiec, A. (2003). Nazwy handlowe i ich uwarunkowania społeczno-komunikacyjne (od kultury zideologizowanej do kultury skomercjalizowanej i reklamy) [Trade names and their social and communication conditions (from ideological culture to commercialized culture and advertising)]. W: M. Biolik (red.), Metodologia badań onomastycznych [Methodology of onomastic research] (s. 543-555). Olsztyn: Ośrodek Badań Naukowych im. W. Kętrzyńskiego.

Siwiec, A. (2012). Nazwy własne obiektów handlowo-usługowych w przestrzeni miasta [Names of retail and service facilities in the urban space]. Lublin: UMCS. 
Źródła internetowe

http://www.portal.katowice.pl/promocja_cyrulikslaski.php (dostęp: 26.08.2019).

https://migawkacafe.pl (dostęp: 25.05.2019).

https://www.socoffee.pl (dostęp: 25.05.2019).

Znaczenia skrótów graficznych, leksykalnych i słownikowych

$<\quad-$ pochodzi od

$\rightarrow \quad$ - konotuje znaczenie

ang. - angielski

niem. - niemiecki

pot. - potocznie

SGŚ - Podgórscy (2008)

NŚS - Kortko i Jodliński (red.) (2010)

\author{
SUMMARY \\ THE NAMES OF UPPER SILESIAN CAFÉS \\ IN THE SPHERE OF CONSUMPTION CULTURE
}

The article discusses one of the categories of marketing chrematonyms — the names of cafés, which constitute a colourful element of the naming landscape of Upper Silesia. The analysis has several research aims: 1) discovering the naming techniques and types, 2) the presentation of structural models, $) 3$ identifying the changes of meaning and the (con)textual functionality of linguistic units which serve as a commercial medium of evaluation. The names of cafés are presented from the perspective of cultural linguistics, sociolinguistics and pragmalinguistics, as well as the theory of semantic fields. This combined methodological approach enables the author to draw conclusions about marketing chrematonyms in the sphere of culture and language, whereas the structural-semantic analysis of the onymic description of Upper Silesian cafés reveals tendencies that confirm the fact that naming models are created in a serial way. The material presented indicates that commercial chrematonyms belong to semantically and structurally diversified naming categories. The structures show the repetitiveness of naming, the tendency for language internalization and the use of native material, including local dialects.

Keyw ords: chrematonymy, names of cafés, consumption culture, Upper Silesia 